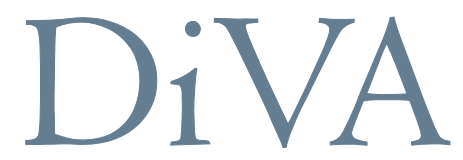

http://uu.diva-portal.org

This is an author produced version of a paper published in Archive for the Psychology of Religion. This paper has been peer-reviewed but does not include the final publisher proof-corrections or journal pagination.

Citation for the published paper:

Liljas Stålhandske, M., Ekstrand, M. \& Tydén, T.

"Existential Experiences and Strategies in Relation to Induced Abortion: an Interview Study With 24 Swedish Women"

Archive for the Psychology of Religion, 2011, Vol. 33, Issue 3: 345-370

URL: http://dx.doi.org/10.1163/157361211X594177

Access to the published version may require subscription. 


\section{Existential Experiences and Strategies in Relation to Induced Abortion: An Interview Study With 24 Swedish Women}

Maria Liljas Stålhandske, PhD, researcher

Uppsala Religion and Society Research Centre

Uppsala university

Box 511

SE 75120 UPPSALA, Sweden

maria.liljas@crs.uu.se

Maria Ekstrand, PhD, Researcher

Department of Public Health and Caring Sciences

BMC, Husargatan 3

Box 564

75122 UPPSALA, Sweden

maria.ekstrand@pubcare.uu.se

Tanja Tydén, Professor

Department of Public Health and Caring Sciences

BMC, Husargatan 3

Box 564

75122 UPPSALA, Sweden

tanja.tyden@pubcare.uu.se

Date: 09-05-2011

Number of words: 7341

Published in: Archive for the Psychology of Religion 2011, 33 (3): 345-370

Acknowledgements: The study is a part of two larger research projects: a multicentre abortion study, involving both medical and humanistic departments at Uppsala University, and a centre of excellence program at Uppsala University: Impact of Religion: Challenges to Society, Law and Democracy. 


\title{
Existential Experiences and Strategies in Relation to Induced Abortion: An Interview Study With 24 Swedish Women
}

\author{
Abstract \\ Induced abortion is as common in religious as secular cultures, but interpretations and ways to \\ handle abortion differ. This study focuses existential aspects of abortion, in relation to a \\ secularized context, through in-depth interviews with 24 Swedish women. Existential questions \\ belonging to four areas were found: Life and Death, Meaning of Life, Morality and Self Image. \\ Furthermore, four different existential strategies were found: (1) Detaching Strategies (creating \\ distance to the pregnancy), (2) Meaning-Making Strategies (relating the abortion to one's \\ worldview), (3) Social Strategies (sharing the abortion with others), and (4) Symbolic Strategies \\ (expressing the experience in bodily ways). Existential questions and strategies did not imply that \\ the woman regretted her abortion. However, while some women easily processed existential \\ questions, others seemed to be more at loss. In a secularized country, where many people are \\ unaccustomed to deal with existential issues, greater existential competence among abortion \\ personnel thus might be needed.
}

\section{Introduction}

Sweden is one of the most secularized countries in the world. No other population has, to as great an extent as the Swedish people, left traditional values in favour of those based on rationality and self-expression (Inglehart \& Baker, 2000). The Swedish population shows a continuously declining interest in institutional religion and a marginal interest in organized forms of spirituality. However, little is known about how individuals think about life and death, meaning and morality, within a context of extreme secularity, and research in the area is needed, as several scholars have pointed out (DeMarinis, 2008; Hill \& Gibson, 2008; la Cour, 2008). 
Secular people - like all human beings - are confronted with life and death, and need to come to terms with the fundamental challenges of being human. When a child is born, when a relative dies or when a marriage breaks up, existential questions about the value and meaning of human life, often come to the surface. Unexpected pregnancy and abortion are similar situations, but abortion is different in one important respect - unlike childbirth and death, abortion is seldom publicly acknowledged, and the event is not related to any religious or social rituals. Moreover, it is an event that occurs due to a woman's conscious decision. This makes abortion a particularly interesting existential area to explore within a secular context.

\section{Aim of the Study}

Little research has been done on abortion within the psychology of religion, and this study thus had an explorative design. The main aim was to find out if existential aspects existed in Swedish women's stories about abortion, and, if they did, what these aspects were and how the women handled them. With its explorative and descriptive outline, the study does not aim to discuss the ethical implications of abortion. The authors have no intention to question the Swedish abortion legislation, which we all endorse.

\section{Abortion in Sweden}

The Swedish abortion law of 1975 permits abortion solely on the request of the pregnant woman until the $18^{\text {th }}$ week of gestation. The right to free abortion is widely accepted in Sweden, to an extent that sets it apart from most other countries. According to the results of the World Values Survey 2005-2008, about 14-15\% of the populations in France, Germany and Finland believed that abortion is never justifiable. ${ }^{\mathrm{i}}$ In the United States this figure was $25 \%$, and in Italy $39 \%$. In Sweden, by contrast, only $2 \%$ held this view. A similar difference was found regarding the proportions of those who considered abortion to be justifiable, and even compared with the other 
Nordic countries, the Swedish population has a distinctively more liberal attitude towards abortion.

Swedish women are fostered within a culture that strongly endorses a woman's right to decide over her body, and abortion is generally not considered a controversial issue. Thus, when a Swedish woman is faced with an unwanted pregnancy this need not be experienced as a big problem. Swedish abortion care is expected to be efficient, safe and professional, and Swedish women are most of all grateful that they have the possibility to decide if and when they want to become mothers.

Although abortion is a common procedure within Swedish health care, with approximately 38,000 abortions each year, Swedish women's existential experiences of abortion mostly remain invisible, and research in the area is limited.

\section{Religion, Secularity and Well-Being}

Research findings from the last decades generally show the positive impact of religious activities and religious coping on both physical and mental health (Ahmadi, 2006; Bontempo, 2004; Ironson \& Kremer, 2009; Laubmeier, Zakowski \& Bair, 2004; Pargament, Ano \& Wachholtz, 2005; Park, 2005; Smith, McColluogh \& Poll, 2003). However, as Park points out, religiosity and spirituality as salutary resources must be understood as part of a reciprocal process between the individual and the society where he or she lives (Park, 2005). In a secularized culture, which emphasizes rationalism and pragmatism, and where the influence of religious institutions generally is weak, it may be more difficult to make use of religious and spiritual resources (Ahmadi, 2006; DeMarinis, 2008; la Cour, 2008). There exists, as la Cour formulates it, ”a natural limitation of secularization" when it comes to events of existential significance. In other words, it might be particularly difficult for secular people to find meaning in challenging 
situations, which cannot be solved by rationality alone. This also includes situations that occur within the medical context, such as abortion. Researchers dealing with secularized contexts have also called for a greater sensitivity to spiritual issues within the medical care systems. There exists a need to include "psycho-spiritiual interventions", and an openness to understand the patient's search for significance and connectedness (Ahmadi, 2006; Bontempo, 2004; Ironson \& Kremer, 2009).

\section{Existential Questions}

As with the concept "religion", there exists no consensus on how to define "existential questions". In the American context "spirituality" is a more frequently used term, also defined in a number of ways. However, this concept is more difficult to apply to the Scandinavian context. In the lack of a stringent and culturally neutral definition, if such at all is possible, research in this area has to rely on working definitions. Valerie DeMarinis uses the concept "existential dimension" to discuss the individual's ways of creating meaning in life. This includes worldview conception and life approach as well as expressions of symbolic significance (DeMarinis, 2003). In this study, existential questions and experiences are those that are related to the fundamental aspects of human life, such as: mortality, identity, meaning and morality. Meaning-making refers to an individual's cognitive effort of sorting the existential experiences into a comprehensible and meaningful whole (see Park, 2005). We will also refer to symbolic and ritual strategies, and hereby mean, close to Catherine Bell's understanding of ritualisation, practices that in one way or another are distinguished from everyday life (Bell, 1992; Liljas Stålhandske, 2005).

Our approach to life forms the foundation on which we act and make our everyday decisions, and putting this foundation into question creates a mental struggle. As coping theorists have made clear we mostly tend to ask the existential questions when our lives are challenged or 
put at risk in some way (Pargament, Ano, \& Wachholtz, 2005). An unwanted pregnancy might constitute such a situation, forcing a woman to promptly decide if she wants to change her plans for the future, or go through with an abortion.

\section{Abortion from Psychological and Existential Perspectives}

Within psychologically oriented abortion research existential issues have not been a common focus. Researchers in the area have rather concentrated on factors of importance for women's post abortion adjustment, such as: social support, prior mental health problems, personality traits, age, and coping expectancies (Cozzarelli, Sumer, \& Major, 1998; Major \& Cozzarelli, 1992; Major, Richards, Cooper, Cozzarelli, \& Zubek, 1998; Törnbom, 1999; Wilmoth, de Alteriis, \& Bussell, 1992). Most studies also show that severe psychological consequences of early abortion, such as clinical depression, are rare. In the cases where mental health problems follow elective abortion, factors other than the abortion itself better explain this result (Adler, David, Major, Roth, Russo, \& Wyatt, 1992; Gilchrist, Hannaford, Frank, \& Kay, 1995; Kero, Högberg, \& Lalos, 2004; Major, Appelbaum, Beckman, Dutton, Russo, \& West, 2009).

With its focus on the strong and often contradictory feelings to which abortion processes may give rise; current Swedish abortion research does approach the existential domain. In a study combining qualitative and quantitative methods, it was found that few women regretted their decision or experienced long-lasting problems, but that a large group described the abortion in both positive and negative terms - for example relief, loss, pride, guilt, and grief (Kero, Högberg \& Lalos, 2004). Similar results were obtained in men (Kero \& Lalos, 2004). Studies like these make it clear that although abortion must be understood as benign from a psychological perspective, as Major and Cozzarelli conclude, it can involve emotions of existential significance (Major \& Cozzarelli, 1992). 
Some researchers discuss aspects of abortion that are more closely related to the existential area, such as spirituality (Layer, Roberts, Wild, \& Walters, 2004; Thibodeau, 2002), religiosity and gender roles (Wall et al., 1999), beliefs (Fountain, 2007), or religious coping (Major, Richards, Cooper, Cozzarelli, \& Zubek, 1998). Research on existential aspects of health has generally focused on religious coping. As an exception, some studies focusing worldview and spirituality in relation to abortion showed that it was more important for a woman's adjustment after abortion to have a developed worldview or personal spirituality than to have a specified religious faith or to be a member of a particular religious group (Fountain, 2007; Thibodeau, 2002). Thoughts about existential and spiritual issues thus appear to be of importance for women having an abortion.

Only a few studies have looked into ritual as a way of dealing with abortion, and the Japanese ritual Mizuko kuyō is the only culturally acknowledged abortion ritual discussed, where the researchers have debated whether the ritual should be understood as a liberating or conservative and patriarchal practice for Japanese women (Hardacre, 1999; Landres, 1996). Other examples are collected from different forms of therapeutic or other individual settings (Brin, 2004; DeMarinis, 1996; Layer, Roberts, Wild, \& Walters, 2004; O'Connor, 1995).

Taken together, research in the area draws a picture of abortion as an event of existential significance, showing that thoughts and feelings related to the existential domain are not uncommon among aborting women. A number of studies also underline the importance of a qualitative focus on women's thoughts and beliefs when making reproductive choices (Fountain, 2007; Halldén, Christensson, \& Olsson, 2005; Thibodeau, 2002). However, we have found no abortion studies within the psychology of religion field, and no studies that have specifically attempted to outline women's existential questions or ways of handling them. 


\section{Method}

Sample

The sample consisted of women $(n=24)$ aged 21 to 57. The women were recruited at the Student Health Clinic in Uppsala, a mid-sized university town in Sweden, and through an advert in a student magazine. Inclusion criteria were wide, and any woman with previous experience of abortion within Swedish health care was welcome to take part. All women were born in Sweden, except one, and two women had parents born in other European countries. Background data is shown in table 1.

\section{Please insert table 1 about here.}

\section{Study Outline}

The study had an explorative and qualitative design, and we used individual, semi-structured indepth interviews and a questionnaire (developed by the first author) with Swedish-speaking women having previous experience of abortion. We carried out the study between June 2008 and February 2009.

The three authors held the interviews, which lasted between 60-120 minutes. All authors are researchers within sexual and reproductive health and two are also midwifes, both experienced in clinical abortion care. The interviews were performed face to face at the Student Health Clinic, at the research office, or at the informant's workplace. The sessions started with time for the women to fill out the questionnaire, which contained socio-demographic questions and five multiple choice items about thoughts, feelings and practices in relation to the abortion, designed to track existential aspects (items 11-15). These items each included 6 to 14 variables, with response alternatives on a 5-point Likert scale ( $1=$ 'fully disagree' to $5=$ ='fully agree'; table 2).

\section{Please insert table 2 about here.}


When the questionnaire was completed the interview started, and the interviewer encouraged the woman to tell the story about her pregnancy and abortion. The interviewer used an interview guide to make sure all topics of interest were discussed (table 3), and asked the woman to comment on her response to items 11-15 in the questionnaire. The interviewer encouraged each participant to explore her experiences thoroughly by posing additional, complementary open-ended questions, in order to elicit deeper reflection.

\section{Please insert table 3 about here.}

\section{Data Analysis}

The interviews were recorded and transcribed verbatim. The analysis can best be described as abductive, including both deductive and inductive parts (Dubois \& Gadde, 2002; Haig, 2005). In the first stage of the analysis we worked deductively to formulate overarching themes of interest, on the basis of research review and a pilot study. The qualitative pilot study was conducted with four women with previous abortion experience (included in the present study), and six people working with abortion issues as counsellors or within the hospital chaplaincy in Uppsala and Gothenburg. The pilot study underlined the existential significance of abortion, found in the research review, and as our overarching themes we thus settled for existential questions related to abortion and existential strategies related to abortion.

In the second stage of analysis we worked inductively with the interviews through a latent content analysis made in three steps (Graneheim \& Lundman, 2004, Kvale, 1996):

1. The first author read the transcribed text and performed

a. a meaning concentration by constructing condensed stories for each interview

b. a meaning categorisation by identifying and coding meaning units from the complete transcripts and creating preliminary categories that could be sorted under each theme 
c. a meaning categorisation by identifying and coding meaning units from the complete transcripts in terms of how difficult the women described their abortion experiences

2. All authors read the transcripts, and the condensed stories, codes and categories created by the first author. The categories were examined across the whole data set, and the content and boundaries of each category were continually discussed and refined.

3. All coded meaning units, with information relevant to the aim of the study, were referred to eight mutually exclusive categories sorting under the two themes (table 4). The categorization of experienced difficulty resulted in three subgroups: I) Easy experience, II) Somewhat difficult experience, and III) Difficult experience.

Finally we analyzed the questionnaires individually in order to validate the subgroups, according to how the women had replied to the existential items (items 11-15) in the questionnaire. For each item we selected those variables that most specifically signalled some form of existential significance, in total 23 variables (see table 2). We counted the times each respondent had agreed (marked 4-5) to any of these 23 variables. The scores were similar to our interview categorisation; some women had not agreed to any of the selected variables (subgroup I), some women had agreed to 3-8 of the variables (subgroup II), and some women had agreed to 12-15 of the variables (subgroup III). Overall, the interview analysis was consistent with the questionnaire analysis, but some minor changes were made. The questionnaires were also used to obtain socio-demographic data.

The qualitative analysis program Atlas.ti facilitated the analysis. The study was approved by the Regional Ethical Committee in Uppsala (2008/289). Quotations from the informants are presented in the text, followed by interview numbers in parenthesis.

\section{Please insert table 4 about here.}

\section{Results}


Existential questions and experiences were part of almost all of the women's stories and central to several of them. Simultaneously, all the women in the study, except one, were satisfied with having had an abortion, and several of them expressed gratitude for having the opportunity to choose when to give birth. Despite these commonalities, the most important result of the analysis was that the women's experiences of the abortion were so diverse, and that the women dealt with them in very different ways. The eight categories do not describe the chronological process of pregnancy, abortion and recovery. Since existential issues surfaced at very different times for the women, the following presentation is rather formed as a catalogue over the existential issues and practices found in the women's stories.

\section{Existential Questions Related to Abortion}

Existential questions can be posed in a very general manner: What is right and wrong? What is the meaning of life? What is a life? Few people have well developed answers to questions like these. However, as stated earlier, in particularly challenging life situations, individuals are forced to deal with existential issues in very concrete ways. The interviews gave rich examples of this. Facing their unwanted pregnancies, the women had to deal with abstract philosophical dilemmas in relation to their concrete lives: what is right and wrong to do in my situation?; what is the meaning of my existence?; what is a human life according to me?

\section{Life and Death}

A positive pregnancy test shows that a process, which might lead to the birth of a new human being, has begun. But what kind of an entity is it that grows inside the woman's womb? And what happens to it if the pregnancy process is ended? For a number of women the abortion process included thoughts about life and death, and particularly the issue of foetal life. Some women wondered whether the foetus should be understood as a human being or as a part of their 
own bodies. Other women wondered if the foetus had a soul and, if it did, what would happen to it after the abortion. While some had quite distinct answers to questions like these, and could easily relate to them when making their concrete decision, others hesitated or moved back and forth between different understandings:

But, first it was like "this is a lump of cells" and all that, and then after a few days I started to feel sick and things, and then I started to think like "well, maybe this is a child". (IP10)

\section{Meaning of Life}

Thinking about the pregnancy in terms of a "lump of cells" put the abortion decision in a different light, than thinking about it in terms of a "child". But to consider what to do with the unexpected pregnancy was not only related to the status of the foetus. The situation also forced the women to choose between two very different life options. For some women, the choice was obvious and easy. Women who were in the beginning of their studies when they became pregnant often described abortion as the natural choice - education and job first, then family. For others, the situation initiated more encompassing questions about life and its meaning. These women started to ask themselves what they really wanted out of life, and what really was of ultimate importance for them. Was the desire to have children and a family as strong as their hope for education or a good career? And if so - should education or career be postponed because of the pregnancy, or should the pregnancy be ended in the hope of more stable circumstances to form a family in the future?

The meaning of life... is it really the meaning that I should only work work work work work and work? There must be something more, something bigger - something more important than the job. (IP15)

\section{Morality}

For some women the abortion was not only a question of personal desires and values - but of morality. Regardless of my needs - what is the right thing to do in this situation? Although Swedish women have a legal right to abortion, some women reported feelings of guilt or remorse. 
I felt guilty facing the doctor. I really did. Do I really have a good reason to have an abortion, or is it just that it's about me and my own wants, that I don't really have the energy [to carry a pregnancy to term]? /---/ I kind of felt that "can one really have an abortion when one is married and has two kids and a job?", I guess that's what I felt. (IP16)

For the women who struggled with moral questions, the legal right to abortion did not eliminate the need to process ethical issues. Having the right to abortion did not mean all women found it easy to argue for abortion as the right thing to do in their specific situations. Almost all women endorsed the Swedish abortion legislation, but few of them had developed a personal moral understanding of the issue. As they were confronted with their pregnancies they had to argue in favour of abortions not only as an abstract principle, but as a personally justifiable choice. This could be difficult, either because the woman herself was uncertain of her choice, or because she felt that other people might question it. For some, the struggle to find a firm ground for their decision continued for a long time - also after the abortion was completed.

\section{Self Image}

Finally, the self image of many of the interviewed women seemed to have been challenged by the unexpected pregnancy and the decision to terminate it. Feelings of shame set off questions like: what kind of a person am I, and what kind of a person do I want to be? This could sometimes be related to the idea that there is a specific kind of women who have abortions - and that the women did not see themselves as belonging to that category.

And I really felt like "Ugh, what am I doing here", you know... "This isn't me", and I know that I said it at least ten times to the doctor I met "just so you know, I'm a very conscientious person". I pointed this out several times. (IP8)

New and positive aspects could also be added to the women's images of themselves. Several women, who had not earlier been pregnant, discovered new feelings of femininity and maternity. The situation made these women realize for the first time in their lives that they really could become mothers and have a family, something which they had not previously given much 
thought to. This could be an enjoyable and strengthening experience for the women - but it could also make it more difficult to go through with the abortion.

I felt so typically pregnant, you know /---/ all of a sudden I started to feel very womanly. It felt like... well, it was new, you know, to feel so womanly... and when I felt that way I really wanted to keep the pregnancy, because it was such a nice feeling. (IP14)

\section{Existential Strategies Related to Abortion}

The existential questions, described above, display the dilemmas that the women described in relation to their pregnancies and abortions. Some of these dilemmas could be resolved by an answer to a straightforward question: do I see the foetus as a human life or not? However, when

looking at how the women handled the existential issues we found that they developed a number of different strategies - of which some were related to cognitive, and others to social or symbolical processes and needs. Furthermore, some women quite easily found ways to handle the situation, and spontaneously developed the tools they needed. Others had to struggle to find their ways to express and deal with the situation, and of these, some still seemed to be looking for ways to conclude the process.

\section{Detaching Strategies - To Create a Distance From the Pregnancy, In Order To Avoid Difficult} Emotions

The women used a number of different words when talking and thinking about their pregnancies. "Pregnancy", "foetus”, “embryo", “child”, "baby”, and "beginning life” were the more common words used in the interviews. For some women the labelling of the pregnancy seemed to have been of great importance for how they felt about their abortions, since more detached words made the thought of abortion easier. Using detaching as a strategy these women more or less deliberately chose how to think about their pregnancies in order to avoid difficult emotions.

One can turn it [the understanding of the pregnancy] in any direction one wants, and I turned it to my advantage. /---/ I don't know if it was a defence mechanism, but that's how it was. (IP13) 
Many women described the period of waiting for the abortion as difficult, since the continuing development of the foetus made a detached understanding of the pregnancy more complicated.

To me it felt as if I had a tumour growing inside, and then it felt $\mathrm{OK}$ to have an abortion. But to let this child, or child to be, to grow and become more and more human, that felt totally, totally horrible... having to wait for it for several weeks, you know. (IP5)

A number of women also pointed out the importance of distinguishing the unwanted pregnancy from the idea of a future wanted pregnancy. Here the detaching strategy was not focused on the foetus, but rather on the whole event of being pregnant.

When I want to get pregnant and have kids I will follow every advice. I won't eat fish from the Baltic sea and I won't drink alcohol and I won't smoke at parties... Now there was partying and party smoking and everything like that /---/ I really felt like it marked the difference for me, you know [from a wanted pregnancy]. (IP8)

\section{Meaning-Making Strategies - To Relate the Experience to One's Worldview, In Order To Make It} Morally Acceptable

Thinking about the pregnancy and the foetus for some women also lead to a more encompassing process of connecting the abortion experience to their overall worldviews. The unexpected pregnancy forced some women to choose between their cherished values, since the situation could create a collision between ideals like independence and procreation, or faithfulness and maternity. For one woman, the pregnancy was wanted, but since she did not know for certain whether her boyfriend was the father, it became impossible for her to carry the child to term. Her effort of creating meaning included describing the pregnancy in terms of "a sibling of her coming children", and considering the abortion to be "an act of love".

I mean, there I was carrying a child which I had longed for...but it became a small act of love too in a sense that there shouldn't be any doubt whatsoever of who the father is. So, if one wants to look at it more harshly, one could say that I sacrificed my child to prove my love and my conviction towards my partner (IP4).

Another woman found support in her personally developed view of life. Instead of a god, she believed in a big soul from which all souls emanate, and to which all souls return after death. She 
could easily fit her abortion experience into this understanding, referring to the foetus as a soul that can return. This made it possible for her to view the abortion as an act that

/---/ prevented it [the soul of the foetus] from becoming an earthly person right now, you know, but nothing more than that, and that isn't the worst that can happen to a soul. (IP6)

The abortion thus became morally acceptable and the woman argued that the soul of the aborted foetus is now waiting for another opportunity to be born. One of the two women in the study who had a belief in a personal God related her view of the foetus to her religious belief. For this woman the decision was difficult, and made under pressure from her partner, but she found comfort in understanding the pregnancy as a gift, and the abortion as a way of returning this gift to God:

God saw that I felt this child was a gift, but that I couldn't receive it, and then there was someone else who loved this child and received it. (IP9)

Some had still not found a way to put the pieces together. This was the case, for example, for one woman, who described the meaning of life as creating life, and who did not know how to relate this view to her abortion. Another case was the woman who was principally against abortion, but was persuaded to have one, and did not know how to come to terms with this afterwards. For other women the trouble was related to their competing views of the pregnancy, where experiences of connectedness to the foetus sometimes collided with their decision to postpone motherhood.

Social Strategies - To Share the Experience With Others, In Order To Gain Acknowledgment and Acceptance

To talk about the abortion with their partner, friends and relatives was an important strategy for most of the women. By sharing the experience with people who did not question or judge them, the women felt accepted and less alone, especially when they realized that experiences of abortion are very common. As a strategy for dealing with existential questions, the social strategy 
must be distinguished from the common need to share emotional experiences of other kinds. In other words, this strategy refers to social ways of dealing with existential aspects or experiences of the abortion - particularly feelings of shame or guilt. Although most women found support in sharing their experience with someone, many of the women also found it difficult to talk about the abortion and almost all women conveyed a wish that it would be easier to speak about abortion. One woman compared telling about her abortion with her experience of "coming out" as bisexual, and others described the experience of telling as particularly intense:

It was like coming out, in that I thought it was really hard to tell people in the beginning because I was still quite upset about it and so on. I remember thinking several times that "Now I'm going to say it" but then I just "No, I can’t do it". (IP5)

I told about it at work /---/ it was really tough at first... just to say these words out loud for the first time to someone: "I'm pregnant, I'm going to have an abortion". [I said it] and then I burst out in tears. (IP15)

Although social support seemed to have been crucial for most of the women it was also clear that talking about the experience in itself was not always sufficient. To be able to conclude the experience some also seemed to need more symbolic ways of expressing themselves.

Symbolic Strategies - To Express the Experience in Bodily Ways, In Order To Handle Its Emotional Significance

Symbolic or ritual strategies were part of several of the women's stories, but in different ways.

While some quite deliberately developed or made use of symbolic or ritual forms to deal with the experience, others described more mundane activities as symbolically significant - the activities were ordinary, but performed in a way that set them apart, made them special. One woman had what she herself called "a ceremony", together with her boyfriend. This woman wrote a letter to the child she could have had and placed it on an outdoor stone altar.

[By writing the letter] it felt like completely finished, you know. It felt good. We simply felt that we had to do it, or as if we should do something. (IP6) 
Another woman made figures of clay, representing the foetuses of her two abortions. She brought these figures to the countryside where she buried them. A less ceremonious example is the retreat to nature as a symbolically significant event, which some women described:

I think I sat on a rock in the woods afterwards... and just thought, sat breathing on a rock in the woods and just felt that "now I have done this and... this is how it turned out. Now I'm just breathing." (IP16).

A walk in the woods might seem insignificant, but the ability to frame a pause like this as a special moment, a time to assimilate the experience, was something other women expressed they were unable to do - since life had to go on, and there was never time to think things over. Other symbolic strategies found in the material were: to hold the aborted foetus, to go to church, to paint pictures, to burn a suicide letter, to light a candle, to take yoga classes, to hug a tree and to write about the abortion on a website. Some women also mentioned the use of alcohol in symbolic terms - either as a way to respect the pregnancy, or as a way of making easier to go through with the abortion:

I didn't drink any alcohol during that time and... like just to respect in some way that which was there. That I had to take the consequences, you know. Maybe like a small punishment for myself, you know, that I really must take responsibility and abstain from alcohol and tobacco, you know. (IP14)

This I am a bit ashamed of, but two days before or something like that, I had like five glasses of wine or something, thinking that now it's too late anyway. Now it has to be done, because I have ruined everything anyway. (IP7)

A symbolic strategy related to abortion was for many of the women a new and sometimes rather strange thought. Some argued that although it was important to work through and end the process, this did not have to be done in a symbolic way. In contrast to this, a number of women also described how they missed some form of symbolic ending of the process, and did not know how they could find it - primarily because of a lack of a religious or existential context and knowledge. For one woman a symbolic funeral would have been an appropriate way to deal with 
the process, but she thought this might "sound strange". Another woman failed to find a way to end the process, since she had no faith:

If you are religious, you would be able to go to church and light a candle or have a séance or something... but I don't know what you do if you don't believe in anything. If you are to have some symbolic ritual it has to be something that you at least believe in a little. (IP2)

Lack of belief made it difficult for some of the women to make use of symbolic resources, sometimes also because church was associated with abortion resistance. For the women whose abortion stories included a lot of existential thoughts and feelings it seemed vital to let the process come to a conclusion. Those who had not managed to do so described how thoughts and feelings connected to the abortion still occupied them, or how they suspected that they would come back if and when they took the time to be more introspective.

Well, I haven't felt it has been concluded... after the abortion. It still feels rather... you know... ongoing or present, but my boyfriend has thought that "yes, but so what - we did it, it was a long time ago", you know. "Isn't it finished"? But it isn't finished, for me. (IP18)

I think I am aware of the fact that it isn't really concluded and that I have to actively do something to conclude it... in some way. (IP3)

\section{Difficulty of Existential Issues}

Although the majority of the interviewed women gave different examples of existential issues and strategies, this did not mean all women were deeply troubled by their abortions. The women experienced the existential questions and insights related to the abortion as more or less significant and more or less difficult to deal with. Some women experienced the abortion as a simple procedure most of all resulting in relief. They found the existential thoughts quite easy to deal with, and described the abortion process as nothing particularly difficult, despite the questions it raised for them. For other women the existential thoughts were related to more negative emotions of grief, emptiness or guilt - even though they were satisfied with the decision. 
Moreover, it was not only the women who were ambivalent about the abortion that experienced the process as difficult in some way. Eight of the women who easily decided for abortion also experienced negative emotions and found the process following the decision as complicated to different extents. This also seemed to have surprised some of the women, who had thought of abortion as much more easy to go through - both physically and psychologically:

I believed that it would be a simpler, easier procedure than it was. In some way, it sounded so easy just to take a pill and have an abortion. But I didn't realize that it for example would be so painful, and that it... well... is such a big thing to think about, you know. (IP14)

Some of the women also described how the existential issues initiated processes that were more encompassing and where the questions, thoughts and feelings related to the abortion remained important for several months or even years. These women often described the abortion process in terms of a crisis or a mild depression.

I was really dejected afterwards. I couldn't continue my studies... or I couldn't complete them. I kept studying all semester, but I didn't complete any courses. Didn’t pass the exams. (IP18)

The first year I thought about it exactly every week, when it was the same day of the week [as the abortion]... and now, I think of it maybe... well, often now too. Very often. (IP9)

Some of these women got help from counsellors or psychotherapists and several described how the crisis also led to a process of personal development and maturation, which they could appreciate when looking back.

I can look back now and see that it [my personal process] starts somewhere in, you know, the abortion process and then... it's the kind of thing that moves on. And which has gotten me to start working on things. (IP15)

I felt like "Shit, this is how it's like to be a grown up". You have to make these kinds of hard decisions. I was like forced to make the decision and I am forced to live with it. So really... that's what it feels like... that one maybe matures. (IP18)

\section{Discussion}

Women's psychological responses to abortion vary considerably. This study adds to our previous knowledge about the factors that can contribute to a woman's post abortion reactions, pointing 
out that an abortion can evoke a number of existential issues and that women have different needs and abilities to deal with these. The study furthermore makes clear that the occurrence of existential issues does not imply that abortion is a traumatic or detrimental event. Rather, it means that the event is significant, and can give rise to both positive and negative emotions and processes - which women can find more or less easy to handle. Earlier studies have underlined that psychological distress after abortion is more likely if you are ambivalent about the decision, and our study does not question these findings (Major \& Cozzarelli, 1992). However, our results also underline that an easily made abortion decision not necessarily leads to an uncomplicated process. A number of women, who easily decided to have an abortion, had a lot of existential thoughts, and some of them described how they became overwhelmed with the thoughts and feelings to which the abortion process came to give rise.

Different background factors (such as reasons for the abortion, social network or prior mental health status) are of course crucial to understand why a woman find certain existential issues difficult to process (Major, Appelbaum, Beckman, Dutton, Russo, \& West, 2009; Major \& Cozzarelli, 1992). This study suggests that lack of existential practice might be another factor, particularly related to secularized cultural contexts. Some women in our study clearly had difficulties formulating what they thought or felt during the abortion process. They could stress how they felt a need to conclude the process, yet did not have appropriate symbolic or ritual ideas to do so. In a rationalistic climate like the Swedish, existential and symbolical issues are marginalized, and ritual needs, as Marianne Wan-Hay Chow concludes in her cultural abortion study, might therefore be difficult to express or fulfil (Chow, 2003). In a study of religious coping among cancer patients in Denmark, Peter la Cour comes to a similar conclusion. He argues that specific attention needs to be focused on groups that have been raised in a non-religious environment, since they often lack words and concepts to deal with existential issues - a situation 
which Liljas Stålhandske describes as ritual and existential homelessness (la Cour, 2008; Liljas Stålhandske, 2005).

From a worldview perspective, the lack of structuring narratives might also add to the understanding. In DeMarinis (2008) existential worldview typology she outlines two types specifically related to the secularized context: mixed worldview and lacking worldview function. These types are added to the four types developed by Wulff (1997): transcendent/literal, transcendent/symbolic, non-transcendent/literal and non-transcendent/symbolic. The two types DeMarinis adds refer to a conscious rejection of a single meaning system or a lack of functioning meaning system, described as by-products of the postmodern lifestyle. DeMarinis argues that particularly the lack of functioning meaning-making is a challenge for Swedish society, since a growing number of young people in Sweden lack structuring narratives, decisional pathways and health-promoting rituals (DeMarinis, 2008). In this study is was difficult to distinguish between the two new types that DeMarinis adds to Wulff's model. Most of the women expressed mixed worldviews, but simultaneously displayed a lack of worldview resources and abilities to interpret or work through the experience.

Sometimes I believe in destiny. Or... you know... not that everything is predestined but somehow I believe that everything has a meaning. Although, to be true I don't believe in that because that would mean there is something that rules and I don't believe in that. Ehm... no, I don't know. /---/ I want to... want to believe there is a meaning with everything. (IP16)

The challenge for the women, in terms of worldview, often seemed to be that of choosing the right parts of their worldview cluster to interpret the situation - particularly in relation to how the pregnancy should be understood. The lack of a developed worldview function seemed to make this task difficult for many of the women.

\section{Limitations}


Being recruited at a Student Health Clinic, the women of the present study were quite homogeneous regarding social class and education. However, the interviews showed that while some women wanted to participate in order to tell other people how difficult abortion could be, others took part in order to describe how unproblematic their abortion was. Both groups had the intention to balance what they understood to be the common view of abortion in the Swedish society. The result is a rich material including abortion experiences of very different kinds.

The retrospective outline of the study is important to bear in mind. The material consists of twenty-four women's memories of abortions that had taken place between one month and nine years ago. The women thus had very different distances from their experiences, and their stories were probably influenced by other events in their lives. Many of the interviews showed that the women's existential experiences related to abortion had developed over time - but so had also their ability to formulate them. A number of women conveyed that they had needed to get some distance to the experience in order to understand its emotional and existential implications. Abortion research conducted shortly after abortions might therefore miss important aspects of a woman's emotional and existential process.

\section{Conclusion}

Although abortion is not linked to severe psychological reactions, its emotional and existential consequences should not be underestimated. Earlier studies have pointed out that both positive and negative emotional reactions related to abortion are common, and that these reactions can initiate processes of personal development. The present study supports the conclusion that abortion can be an important and meaningful life event. Many women find ways to include the abortion experience in their personal narratives about development and maturation. The 
experience is thereby related to the woman's worldview and can as such become an asset in her future reproductive life.

However, the study also adds the insight that women in a highly secularized culture as Sweden might have difficulties expressing and dealing with the existential issues that an abortion can evoke. This constitutes an overlooked possibility in abortion care and prevention, since it is not until a woman has a personally developed understanding of what abortion means to her that she can make a fully independent reproductive choice. Finding appropriate ways to help women talk about and express their existential experiences, Swedish abortion personnel could therefore add a significant aspect to an otherwise well developed area of care. 


\section{References}

Adler, N. E., David, H. P., Major, B. N., Roth, S. H., Russo, N. F., \& Wyatt, G. E. (1992). Psychological factors in abortion. A review. The American Psychologist, 47(10), 11941204.

Ahmadi, F. (2006). Culture, Religion and Spirituality in Coping: The Example of Cancer Patients in Sweden. Studia sociologica Upsaliensia. Uppsala: Acta Universitatis Upsaliensis (AUU).

Bell, C. (1992). Ritual Theory, Ritual Practice. New York: Oxford University Press.

Bergin, A. E., Masters, K. S., Richards, P. S. Religiousness and mental health reconsidered: A study of an intrinsically religious sample. Journal of Counseling Psychology, 34(2), 197204.

Bontempo, A. M. (2004). Making Meaning out of Mayhem: A Grounded Theory of Resiliency, Relationship, and Women Coping with Breast Cancer. Retrieved from Dissertation Abstracts International: Section B: The Sciences and Engineering.

Brin, D. J. (2004). The use of rituals in grieving for a miscarriage of stillbirth. In J. C. Chrisler (Ed.), From Menarche to Menopause: The Female Body in Feminist Therapy. New York: The Haworth Press.

Chow, M. W. (2003). Coping with Silence: Comparative Analysis of Post-Abortion Grief in Japan and the United States. Tufts University.

la Cour, P. (2008). Existential and religious issues when admitted to hospital in a secular society: Patterns of change. Mental Health, Religion \& Culture, 11, 769-782.

Cozzarelli, C., Sumer, N., \& Major, B. (1998). Mental models of attachment and coping with abortion. Journal of Personality and Social Psychology, 74(2), 453-467.

DeMarinis, V. (1996). Transplanting rites: The psychosocial role of religious ritual in cross- 
cultural adjustment. In V. DeMarinis \& O. Wikström (Eds.), Clinical Psychology of Religion: Emerging Cultural and Multicultural Questions from European and North American Voices. Stockholm: Forskningsrådsnämnden.

DeMarinis, V. (2003). Pastoral Care, Existential Health, and Existential Epidemiology: A Swedish Postmodern Case Study. Stockholm: Verbum.

DeMarinis, V. (2008). The impact of postmodernization on existential health in Sweden:

Psychology of religion's function in existential public health analysis. Archive for the Psychology of Religion / Archiv für Religionspychologie, 30, 57-74.

Dubois, A., \& Gadde, L. (2002). Systematic combining: an abductive approach to case research. Journal of Business Research, 55(7), 553-560.

Fountain, T. M. (2007). The Effects of Beliefs and Coping on Emotional Response to Surgical Abortion. Walden University. Retrieved from http://gradworks.umi.com/32/44/3244319.html

Gilchrist, A., Hannaford, P., Frank, P., \& Kay, C. (1995). Termination of pregnancy and psychiatric morbidity. The British Journal of Psychiatry, 167(2), 243-248.

Graneheim, U. H., \& Lundman, B. (2004). Qualitative content analysis in nursing research: concepts, procedures and measures to achieve trustworthiness. Nurse Education Today, 24(2), 105-112.

Haig, B. D. (2005). An abductive theory of scientific method. Psychological Methods, 10(4), 371-388.

Halldén, B., Christensson, K., \& Olsson, P. (2005). Meanings of being pregnant and having decided on abortion: Young Swedish women's experiences. Health Care for Women International, 26(9), 788.

Hardacre, H. (1999). Marketing the Menacing Foetus in Japan. University of California Press. 
Inglehart, R., \& Baker, W. (2000). Modernization, cultural change, and the persistence of traditional values. American Sociological Review, 65(1), 51, 19.

Ironson, G., \& Kremer, H. (2009). Spiritual transformation, psychological well-being, health, and survival in people with HIV. The International Journal of Psychiatry in Medicine, 39(3), 263-281.

Kero, A., Högberg, U., \& Lalos, A. (2004). Wellbeing and mental growth-long-term effects of legal abortion. Social Science \& Medicine (1982), 58(12), 2559-2569.

Kero, A., \& Lalos, A. (2004). Reactions and reflections in men, 4 and 12 months post-abortion. Journal of Psychosomatic Obstetrics \& Gynecology, 25(2), 135-143.

Landres, J. S. (1996). Symbolic subject, subjected symbol: Mizuko Kuyo, gender and the social order in Japan. Journal of Contemporary Religion, 11(1), 57-67.

Laubmeier, K. K., Zakowski, S. G., \& Bair, J. P. (2004). The role of spirituality in the psychological adjustment to cancer: A test of the transactional model of stress and coping. International Journal of Behavioral Medicine, 11(1), 48-55.

Layer, S. D., Roberts, C., Wild, K., \& Walters, J. (2004). Postabortion grief: Evaluating the possible efficacy of a spiritual group intervention. Research on Social Work Practice, 14(5), 344-350.

Liljas Stålhandske, M. (2005). Ritual Invention: A Play Perspective on Existential Ritual and Mental Health in Late Modern Sweden. Uppsala: Uppsala University.

Major, B., Appelbaum, M., Beckman, L., Dutton, M. A., Russo, N. F., \& West, C. (2009). Abortion and mental health: Evaluating the evidence. American Psychologist, 64(9), 863890.

Major, B., \& Cozzarelli, C. (1992). Psychosocial predictors of adjustment to abortion. (G. H. Wilmoth, Ed.) Journal of Social Issues, 48(3), 121-142. 
Major, B., Richards, C., Cooper, M. L., Cozzarelli, C., \& Zubek, J. (1998). Personal resilience, cognitive appraisals, and coping: An integrative model of adjustment to abortion. Journal of Personality and Social Psychology, 74(3), 735-752.

O'Connor, J. (1995). Ritual recognition of abortion: Japanese Buddhist practices and U.S. Jewish and Christian proposals. In L. S. Cahill \& M. A. Farley (Eds.), Embodiment, morality and medicine, Theology and Medicine (Vol. 6). Dordrecht, Netherlands: Kluwer Academic Publishers.

Park, C. (2005). Religion and meaning. In R. F. Paloutzian \& C. L. Park (Eds.), Handbook of the Psychology of Religion and Spirituality (pp. 295-314). New York: Guilford Press.

Pargament, K. I., Ano, G. G., \& Wachholtz, A. B. (2005). The religious dimension of coping: Advances in theory, research, and practice. In R. F. Paloutzian \& C. L. Park (Eds.), Handbook of the Psychology of Religion and Spirituality (pp. 479-495). New York: Guilford Press.

Smith, T. B., McCollough, M. E., \& Poll, J. (2003). Religiousness and depression: Evidence for a main effect and the moderating influence of stressful life events. Psychological Bulletin, $129,614-636$.

Thibodeau, A. M. (2002). Spiritual Well Being and Adjustment to Abortion. Buffalo: State University of New York.

Törnbom, M. (1999). Psychosocial Factors Related to the Choice of Legal Abortion. Göteborg: University of Gothenburg.

Wall, S. N., Frieze, I. H., Ferligoj, A., Jarosova, E., Pauknerova, D., Horvat, J., \& Sarlija, N. (1999). Gender role and religion as predictors of attitude toward abortion in Croatia, Slovenia, the Czech Republic, and the United States. Journal of Cross-Cultural Psychology, 30(4), 443-465. 
Wilmoth, G. H., de Alteriis, M., \& Bussell, D. (1992). Prevalence of psychological risks following legal abortion in the U.S.: Limits of the evidence. (G. H. Wilmoth, Ed.) Journal of Social Issues, 48(3), 37-66.

Wulff, D. M. (1997). Psychology of Religion: Classic and Contemporary. New York: John Wiley \& Sons. 


\section{Tables}

\section{Table I. The sample}

Number of women $(n=24)$

1. Age at interview, years
$20-29$
$30-39$
$40-49$
$50-59$

2. Occupation at interview

University student

10

Doctoral student

2

Employed

10

Sick leave/unemployed

1

No answer

1

3. Concluded education

Up to high school (gymnasium) 10

College or university 14

\section{Ethicity}

Born in Sweden, parents born in Sweden

Born in Sweden, one of parents born outside Sweden

5. Time since (last) abortion

$<1$ year ago

1-4 years ago

$5-9$ years ago

$>9$ years ago

6. Age at (last) abortion

15-19 years

20-24 years

25-30 years

7. Abortion method at (last) abortion*

Surgical abortion

Medical abortion

Mid-trimester abortion (> 13 weeks)

8. Number of re-abortions in sample

9. Gestation week at (last) abortion

Before gestation week 12

10. View of life at interview*

I believe in a personal God

I believe in an impersonal power or force of life

3

I believe in something spiritual in nature or human beings

I don't know what to believe

I do not believe in a god, power or force of life

No answer

* Some women responded in more than one way on questions 7 and 10. 


\section{Table II. Items 11-15 in the questionnaire}

Item from questionnaire

Variables (Answered with 5-point Likert-scale)

11. When I look back to the time of the abortion and immediately after it, I think 1) Emptiness; 2) Responsibility; 3) Impatience; 4) Shame; 5) Powerlessness; 6) the following words describe how I felt: Maturity; 7) Indifference; 8) Grief; 9) Guilt; 10) Independence; 11) Anger; 12) 12. In relation to the abortion I thought Relief; 13) Love; 14) Resignation 15) Other... especially about: 1) My body and fertility; 2) My close relations; 3) My future; 4) The meaning of 13. In relation to the abortion I thought life; 5) Life and death; 6) Guilt and moral; 7) Other... about that which was/had been in my 1) A pregnancy; 2) An embryo or fetus; 3) A clot of cells; 4) A beginning life; 5) A womb in terms of:

14. In relation to the abortion I had wanted to do/I did a special act in order to:

15. After the abortion I have: child; 6) A soul that can return, 7) Other...

1) Mark what had happened; 2) Conclude the process; 3) Let off steam; 4) Feel at home again in my body; 5) Grieve; 6) Ask for forgiveness; 7) Be reconciled with it all; 8) Other...

1) Felt that everything concerning the pregnancy was over; 2 ) Wished that it would be easier to talk about abortion; 3) Wondered what had happened to the fetus; 4) Thought about the child I could have had; 5) Wished I could go someplace to work things through or mourn; 6) Thought about the child as an angel; 6) Not wanted to think any more about it; 7) Other...

* Variables displayed in bold = variables selected for subgroup validation 
Table III. Interview guide

\section{Topic Questions}

\begin{tabular}{l}
\hline The decision \\
\hline Tell me about the pregnancy, was it unexpected? \\
\hline Tell me about the decision, how did you decide what to do? \\
\hline Was there something in particular that led to the decision? \\
\hline The process \\
\hline What happened then - waiting for the abortion, the abortion, afterwards? \\
\hline How did it feel then? How does it feel today? \\
\hline What are your thoughts about children and family in the future? \\
\hline If you could go back in time, is there anything you would like to change in the process after becoming pregnant? \\
\hline Social support \\
\hline Did you tell anyone that you were pregnant? If yes, whom? \\
\hline How did you feel people responded to and treated you during that period? \\
\hline How did you feel the personnel at the clinic treated you? \\
\hline How did it feel to talk about the abortion? \\
\hline Feelings, thoughts and practices (these questions refer to items in the questionnaire) \\
\hline Would you like to tell me a bit more about your faith or worldview? (Item 6) \\
\hline Would you like to tell me a bit more about your feelings related to the abortion? (Item 11) \\
\hline Would you like to tell me a bit more about your thoughts related to the abortion? (Item 12 and 13) \\
\hline Would you like to tell me a bit more about your practices related to the abortion? (Item 14) \\
\hline Would you like to tell me a bit more about your thoughts and feelings after the abortion? (Item 15)
\end{tabular}


Table IV. Presentation of themes and categories

Deductive themes

\begin{tabular}{ll}
$\begin{array}{l}\text { Existential Questions Related } \\
\text { to Abortion }\end{array}$ & Existential Strategies Related to Abortion \\
$\begin{array}{l}\text { Life and death - issues about } \\
\text { the essence and borders of } \\
\text { human life }\end{array}$ & $\begin{array}{l}\text { Detaching strategies - to create distance } \\
\text { from the pregnancy, in order to avoid } \\
\text { difficult emotions }\end{array}$ \\
\hline $\begin{array}{l}\text { Meaning of life - issues about } \\
\text { the meaning and fundamental } \\
\text { values of life }\end{array}$ & $\begin{array}{l}\text { Meaning-making strategies - to relate the } \\
\text { experience to one's worldview, in order to } \\
\text { make it morally acceptable }\end{array}$ \\
\hline $\begin{array}{l}\text { Morality - issues about what } \\
\text { is right and what is wrong }\end{array}$ & $\begin{array}{l}\text { Social strategies - to share the experience } \\
\text { with others, in order to gain } \\
\text { acknowledgment and acceptance }\end{array}$ \\
\hline $\begin{array}{l}\text { Self image - issues about who } \\
\text { one is and who one wants to } \\
\text { be }\end{array}$ & $\begin{array}{l}\text { Symbolic strategies - to express the } \\
\text { experience in bodily ways, in order to } \\
\text { handle its emotional significance }\end{array}$
\end{tabular}

\footnotetext{
${ }^{\mathrm{i}}$ The World Values Survey (WVS) is a global network of social scientists who have surveyed the basic values and beliefs of the publics of more than 80 societies, on all six inhabited continents from the 1980's and continuing. The abortion item in the WVS questionnaire is formulated "Please tell me whether you think abortion can always be justified (10), never be justified (1), or something in between (2-9)".
} 